\title{
Exploring the complex relationship between women's sanitation practices and household diarrhea in the slums of Nairobi: a cross-sectional study
}

\author{
Samantha Winter ${ }^{1 *}$ (D) Millicent Ningoma Dzombo ${ }^{2}$ and Francis Barchi ${ }^{1}$
}

\begin{abstract}
Background: Diarrheal disease kills over half a million people each year in sub-Saharan Africa; the majority are children under 5 years. About $58 \%$ of diarrhea cases are associated with poor water, sanitation, and hygiene-a critical issue for people living in informal settlements. In Kenya, $60 \%$ of Nairobi's population lives in informal settlements; yet, there is a paucity of research exploring the relationship between water, sanitation and hygiene (WASH) conditions in these settlements and associated health outcomes.

Methods: The study examines characteristics of women's WASH behaviors and environments as potential factors associated with household diarrhea in Mathare Valley Informal Settlement in Nairobi using cross-sectional survey data collected from 550 women.

Results: Approximately $17 \%$ of participants reported that at least one member of the household suffered from diarrhea in the previous 2 weeks - $48 \%$ of the cases were children under five. Results from a logistic regression exploring factors associated with reports of household diarrhea suggest that women's sanitation management strategies are associated with recent household diarrhea. Women who use toilets for defecation during the day, but rely on bags, buckets, or open defecation (OD) for urination during the day and for urination and defecation at night have over five time the odds of recent household diarrhea than women who use a toilet for all their sanitation needs. The odds of diarrhea were also higher for participants who walk up to 2 min to reach their toilets/sites for defecation and those who rely on water from taps inside buildings and plots. Odds were $62 \%$ lower for participants with clean toilets.
\end{abstract}

Conclusions: Findings suggest that health targets to reduce the prevalence of diarrheal diseases in informal settlements may not be met unless particular attention is paid to the needs of women living in these environments.

Keywords: Water, Sanitation and hygiene, Women, Informal settlements, Slums, Diarrhea, Developing countries, Kenya

\section{Background}

Globally, diarrheal disease is the 9th largest cause of death among all ages and the 4th leading cause of mortality among children under the age of 5 years [1]. Over $40 \%$ of all-age deaths and more than $60 \%$ of under-5 mortality occurs in sub-Saharan Africa [1]. In 2015, in Kenya, childhood diarrheal disease accounted for 122 deaths per

\footnotetext{
* Correspondence: Winter.samantha@gmail.com

${ }^{1}$ Edward J. Bloustein School of Planning \& Public Policy Rutgers, The State University of New Jersey, 33 Livingston Avenue, New Brunswick, NJ 08901, USA

Full list of author information is available at the end of the article
}

100,000 children and over 790,000 disability-adjusted life years (DALYs) - almost one half of DALYs attributed to diarrheal diseases for Kenyans of all ages [1].

According to some estimates, poor water, sanitation, and hygiene (WASH) are responsible for approximately $58 \%$ of diarrheal-related deaths per year [2]. Other studies suggest the burden of disease associated with poor WASH may be even higher than those previously estimated [3]. Poor water, sanitation, and hygiene are particularly critical health concerns for people living in informal settlements where high population densities combined with a lack of formal waste management strategies, inadequate or absent

(c) The Author(s). 2019 Open Access This article is distributed under the terms of the Creative Commons Attribution 4.0 International License (http://creativecommons.org/licenses/by/4.0/), which permits unrestricted use, distribution, and 
sewers and storm drainages, and inconsistent and often contaminated water supplies increase residents' risk of direct exposure to human feces and consumption of unsafe water [4]. Studies exploring the prevalence of diarrheal diseases in Kenya, especially, have found higher rates for children in urban areas, particularly informal settlements, than in other settings [5]. For example, statistics suggest that over $30 \%$ of children in informal settlements in Nairobi had experienced diarrheal episodes within the prior 2 weeks compared to about $13 \%$ in other parts of Nairobi and 17\% in Kenya as a whole [6, 7]. In Kenya, 60\% of Nairobi's population lives in informal settlements [8]; yet, there is a paucity of research exploring the relationship between characteristics of residents' sanitation and hygiene environments in these settlements and their health outcomes.

The few studies exploring the environmental and socioeconomic factors associated with prevalence of diarrhea in informal settlements in low- and middle-income countries have found important links between several WASH-related factors and the prevalence of diarrheal diseases in these settings. Several studies, for example, have found links between diarrheal infection in children and household drinking water sources $[9,10]$; access to and conditions of sanitation [11, 12]; and caregiver knowledge and practices associated with hygiene and sanitation for diarrhea prevention $[7,9,13]$.

Despite the growing body of literature suggesting important links between WASH-related factors and prevalence of diarrhea around the world, there is still a paucity of empirical research focused on these issues in informal settlements in East Africa, particularly Kenya. In addition, most research focuses exclusively on diarrhea cases in young children. While children under 5 years are the most affected by diarrheal-related morbidity and stunting, diarrhea is a health concern for residents of all ages, especially women [1]. Findings from a recent study in rural Kenya, for example, suggest that female adults have higher incidence of hospitalizations due to diarrheal infections than males [14].

Numerous studies in developing countries have suggested that women, as the managers of household WASH and the primary caretakers of children and elderly and disabled family members, play a critical role in 'breaking the chain of contamination' within their households [15-17]. As the primary caretakers of the home, women are responsible for supplying water for drinking, cooking, bathing, hygiene, and other domestic tasks [16]. Women are also primarily responsible for raising and educating children with regards to WASH and, frequently, for taking care of sick members of the household [16]. These roles and responsibilities put women in a critical position for establishing and maintaining safe and hygienic spaces within the household, ensuring that children form hygienic health- and sanitation-related habits, and helping to minimize illness from preventable diseases [16]. For example, findings from several studies suggest that women's sanitation behaviors and their ability to access sanitation is linked to their children's sanitation behaviors, especially for young children $[18,19]$. Findings from a 2016 qualitative study suggest that one of the factors that influences women's sanitation behaviors in informal settlements in Nairobi is the need to set an example and/or be a role model for their children's sanitation practices [19]. Other studies report that women with small children often take their children with them when they leave the home to access sanitation and/or collect water [20-22] - suggesting that the mother's WASH-related behaviors may be linked to their children's exposure to different environments and, consequently, their health $[16,18]$. Additionally, if a woman lacks the ability to pay to use a public toilet for herself, she is also unlikely to be able to pay for her children to use the public facility-suggesting that both she and her children have to find alternative methods of disposal, such as the use of bags/buckets in the home or open defecation (OD), to meet their sanitation needs [18, 23]. Lastly, women are typically responsible for two other potential sources of household diarrhea: cooking and handling of food and collecting and managing household water supplies [24]. Despite suggestions of a link between women's WASH-related environments or behaviors and household health, there are few studies focusing on this phenomenon. This study is a step towards filling a piece of this gap by examining associations between characteristics of women's sanitation and hygiene knowledge, behaviors and environments and occurrences of household diarrheal disease in an informal settlement in Nairobi, Kenya.

\section{Method}

\section{Data and sample}

Cross-sectional data for this study were collected in 2016 in Mathare Valley Informal Settlement in Nairobi Kenya. Mathare is one of the oldest and largest informal settlements in Nairobi. It is home to approximately 250,000 residents living in an area about $3-\mathrm{km}^{2}$ [25]. The study from which the data were taken focused on women's sociodemographic information, access to and utilization of water and sanitation, health, and neighborhood dynamics in Mathare. Information was gathered from 550 women (50 from each of Mathare's 11 main villages). Households were randomly selected using a grid and random point sampling in ArcMap [26], and individual women were selected from each household using Kish methodology [27]. In order to participate in the study women were required to be 
over 18 years, provide consent to participate, and speak either English or Swahili. The surveys lasted about $60 \mathrm{~min}$.

\section{Measures}

Variables for this study were created from responses to structured questions on the 550 household surveys. The dichotomous outcome variable ( $1=$ "yes"; $0=$ "no") was created from women's answers to the question, "in the last 2 weeks, has anyone in your household had diarrhea?" where diarrhea was defined as passing stool 3 times or more in $24 \mathrm{~h}$ whether watery, bloody, mucoid or water-wash like.

A number of potential diarrhea-related WASH factors were included in the models. Women in this study were asked questions about their primary toilet/ site for urination and defecation during the day and during the night. Responses to these questions were used to identify and characterize five common sanitation utilization profiles for women, which have been previously described in a separate paper [17]. The common sanitation profiles included:

\begin{tabular}{l}
\hline Sanitation Profiles \\
1. Day: toilet for urine/feces; Night: toilet for urine/feces \\
2. Day: toilet for urine/feces; Night: bags/buckets/OD for urine/feces \\
3. Day: toilet for feces, bags/buckets/OD for urine; Night: \\
bags/buckets/OD for urine/feces \\
4. Day: toilet for urine/feces; Night: toilet for feces, \\
bags/buckets/OD for urine \\
5. Day: bags/buckets/OD for urine/feces; Night: \\
bags/buckets/OD for urine/feces \\
\hline
\end{tabular}

Primary drinking-water source is often connected to diarrheal disease [1]; thus, responses to a question about women's primary source for drinking water were collapsed into a four-category water source variable (1. tap inside home, building, or plot; 2 . shared tap outside building or plot; 3. public tap or well; or 4 . tanker or vendor). Questions to measure WASH knowledge, attitudes, and practices (WASH-KAP)—factors, e.g. knowledge of the primary vectors of infection, hand-washing behaviors, and sanitation-related hygiene, associated with diarrhea disease $[2,7,13,28]$-were adapted from questionnaires developed and used in India and South Africa [29, 30]. These included: 1) a measure to indicate a woman's knowledge about WASH behaviors and health; 2) a variable to assess whether or not a woman regularly treated her drinking water; 3) a measure to represent whether a woman regularly used soap/a disinfectant/sanitizer to wash her hands; and
4) a variable to measure whether a woman used tissue for anal cleansing (the most common practice) compared to other methods of cleansing.

The following diarrhea-associated factors related to a woman's primary toilet/methods of urine/feces disposal were also included: 1) whether the respondent felt her toilet/site for urination/defecation was clean $[7,31]$; 2) whether the respondent's toilet/site for urination/defecation regularly had running water [18]; 3) whether a respondent's toilet/site for urination/ defecation had a location for washing hands [18]; 4) the walk time to reach the toilet/site for disposal $(0$ min, less than $1 \mathrm{~min}, 1-2 \mathrm{~min}, 3-4 \mathrm{~min}$, and 5 or more minutes) [11]; and 5) the approximate number of people using the toilet [31]. Finally, several core socio-demographic variables including whether the respondent had children, household income, whether the respondent was married, and respondents' age and education were also included.

\section{Analysis strategy}

Bivariate analyses were run to examine the relationship between recent diarrhea in the household and WASH-related and sociodemographic variables. Variables were tested for multicollinearity using variance inflation factors (VIFs); values were all less than or equal to 3.10. Bivariate analyses suggested that all WASH-related factors were significantly associated with recent household diarrhea except primary water source, use of disinfectant (e.g. soap, sanitizer or ash), and WASH knowledge score. While these three variables were not significantly associated with recent household diarrhea at the bivariate-level, they were included in subsequent regressions as important covariates or potential WASH factors commonly associated with diarrheal disease in the literature [2, 32]. Women's reports of diarrhea in the household in the previous 2 weeks was regressed on all potential diarrhea-related WASH factors using binary logistic regression in Stata Statistical Software, v.15 [33]. Standard errors were clustered by village to account for the fact that 50 surveys were collected in each of Mathare's 11 villages. Although missing values were minimal on individual variables (less than $3 \%$ ), the missing data were imputed using a single imputation method [34].

\section{Results}

\section{Sociodemographic statistics}

Descriptive statistics for the sample are presented in Table 1. Findings suggest that $16.5 \%$ of the women in the sample reported diarrhea in the household in the 
Table 1 Demographic statistics $(n=550)$

\begin{tabular}{|c|c|c|c|c|c|}
\hline & \multicolumn{2}{|l|}{ Total } & \multicolumn{2}{|c|}{ Recent Diarrhea } & \multirow[b]{2}{*}{$x^{2}$} \\
\hline & Freq & $\%$ & No & Yes & \\
\hline \multicolumn{6}{|l|}{ Outcome } \\
\hline Recent diarrhea in household & 91 & 16.5 & 459 & 91 & - \\
\hline Proportion children $<5$ years & 44 & 8.0 & 506 & 44 & - \\
\hline \multicolumn{6}{|l|}{ Socio-Economic Factors } \\
\hline Age (continuous) & $32.2(8.36)$ & - & - & - & $1.03^{* *} \dagger$ \\
\hline Education & & & & & 1.79 \\
\hline Less than complete primary & 102 & 18.5 & 86 & 16 & \\
\hline Completed primary & 136 & 24.7 & 112 & 24 & \\
\hline Some secondary & 122 & 22.2 & 98 & 24 & \\
\hline Completed secondary & 190 & 34.5 & 163 & 27 & \\
\hline Employed & 250 & 45.5 & 198 & 52 & $6.01^{*}$ \\
\hline Married & 299 & 54.4 & 253 & 46 & 0.64 \\
\hline Has children & 449 & 81.6 & 363 & 86 & $12.05^{* *}$ \\
\hline Household income & & & & & $12.27^{* *}$ \\
\hline Less than Ksh 5000/month (US\$50) & 138 & 25.1 & 118 & 20 & \\
\hline Between Ksh 5000-10,000/month & 278 & 50.5 & 218 & 60 & \\
\hline More than Ksh 10,000/month & 134 & 24.4 & 123 & 11 & \\
\hline \multicolumn{6}{|l|}{ Toilet descriptors } \\
\hline Sanitation Profiles & & & & & $46.67^{* * *}$ \\
\hline $\begin{array}{l}\text { Profile 1: Day - toilet for urine/feces; night - toilet for } \\
\text { urine/feces }\end{array}$ & 137 & 24.9 & 122 & 15 & \\
\hline $\begin{array}{l}\text { Profile 2: Day - toilet for urine/feces; night - } \\
\text { bags/buckets/OD for urine/feces }\end{array}$ & 148 & 26.9 & 129 & 19 & \\
\hline $\begin{array}{l}\text { Profile 3: Day - toilet for feces, bags/buckets/OD for } \\
\text { urine; night - bags/buckets/OD for urine/feces }\end{array}$ & 120 & 21.8 & 76 & 44 & \\
\hline $\begin{array}{l}\text { Profile 4: Day - toilet for urine/feces; night - toilet for } \\
\text { feces, bags/buckets/OD for urine }\end{array}$ & 66 & 12.0 & 58 & 8 & \\
\hline $\begin{array}{l}\text { Profile 5: Day - bags/buckets/OD for urine/feces; night - } \\
\text { bags/buckets/OD for urine/feces }\end{array}$ & 79 & 14.4 & 74 & 5 & \\
\hline Relies on public toilet at least once in a 24-h period & 279 & 50.7 & 217 & 62 & $13.21^{* * *}$ \\
\hline \multicolumn{6}{|l|}{ Water source } \\
\hline Primary water source & & & & & 2.02 \\
\hline Tap inside home/building & 74 & 13.5 & 62 & 12 & \\
\hline Tap outside home/building & 89 & 16.2 & 70 & 19 & \\
\hline Public tap or well & 312 & 56.7 & 265 & 47 & \\
\hline Tanker/vendor & 75 & 13.6 & 62 & 13 & \\
\hline \multicolumn{6}{|l|}{ Toilet hygiene and accessibility } \\
\hline Toilet(s) are clean & 340 & 61.8 & 293 & 47 & $4.78^{*}$ \\
\hline Toilet(s) have running water/water for hygiene & 184 & 33.5 & 163 & 21 & $5.27^{*}$ \\
\hline Maximum number of people sharing toilet(s) (continuous) & $152.4(219.37)$ & - & - & - & $1.001^{* *+}$ \\
\hline Maximum walk time to toilet(s) & & & & & $12.64^{* *}$ \\
\hline Does not go outside & 146 & 26.5 & 132 & 14 & \\
\hline 2 min or less & 212 & 38.5 & 164 & 48 & \\
\hline Between 3 and 4 min & 85 & 15.5 & 69 & 16 & \\
\hline At least 5 min & 107 & 19.5 & 94 & 13 & \\
\hline
\end{tabular}


Table 1 Demographic statistics $(n=550)$ (Continued)

\begin{tabular}{|c|c|c|c|c|c|}
\hline & \multicolumn{2}{|l|}{ Total } & \multicolumn{2}{|c|}{ Recent Diarrhea } & \multirow[b]{2}{*}{$x^{2}$} \\
\hline & Freq & $\%$ & $\mathrm{No}$ & Yes & \\
\hline \multicolumn{6}{|l|}{ WASH knowledge and practices } \\
\hline Uses disinfectant (e.g. soap) to wash hands & 453 & 82.4 & 378 & 75 & 0.00 \\
\hline Treats drinking water & 179 & 32.5 & 161 & 18 & $8.09^{* *}$ \\
\hline Uses something other than tissue for anal cleansing & 236 & 42.9 & 183 & 53 & $10.46^{* *}$ \\
\hline WASH knowledge score (continuous) & $13.1(4.08)$ & - & - & - & $1.05+$ \\
\hline
\end{tabular}

2 weeks leading up to the survey, and of those cases, $48 \%$ were children under the age of 5 years. Over half of the sample was married and over $81 \%$ of the women had at least one child. About three-quarters of the women had monthly household incomes of less than KES 10,000 per month (USD 100). Over half the women reported good health. During the day, about half the women reported using a public toilet, $20 \%$ reported using a plot or building toilet, and about $30 \%$ reported using bags or buckets at home. At night, over twothirds of the women reported using bags or buckets at home and about 19\% reported using plot or building toilets. The majority of women (57\%) use a public tap or well for their primary drinking water source followed by an outside tap (16\%), tankers or vendors $(14 \%)$, or a tap inside their home/building (14\%). Out of a possible score of 20, the average score on the WASH -KAP scale was $13(\mathrm{SD}=4.1)$.

\section{Women's knowledge about water, sanitation, and hygiene (WASH - KAP)}

Women in this survey were asked several general open-ended questions (multiple responses were allowed) about WASH and health. A summary of the responses are reported in Table 2. About half of the women in this study (49\%) identified diarrhea as the most common effect from drinking unsafe water followed by cholera (34\%) and typhoid (31\%). While over half of the sample (56\%) felt that everyone is affected by diarrhea, just under $48 \%$ reported that young children are the most affected. In response to the question, 'how does a person get diarrhea', over $80 \%$ of women identified dirty hands $(82 \%)$, germs $(85 \%)$, dirty food $(86 \%)$, poor hygiene $(83 \%)$, and dirty water $(82 \%)$ as the primary causes of diarrhea. Over $60 \%$ also identified flies (69\%) and OD (63\%) as causes. Ninety percent of women reported drinking clean/safe water as the primary practice to prevent getting diarrhea. Washing food before it is eaten (87\%), using a toilet (82\%), treating water (79\%), washing hands with water and soap/ash (78\%), covering food (78\%) and avoiding OD and flying toilets
(70\%) were also common practices identified to prevent diarrhea. In response to the following question, "kindly give me the key times you should wash your hands," almost 99\% of the women said before eating and close to $92 \%$ said after eating. After toilet use (88\%), after defecation (76\%), after handling babies feces/ changing a diaper (73\%), and after handling rubbish (61\%) were also key times.

\section{Diarrhea-related water, sanitation, and hygiene factors}

Results from the bivariate analyses of WASH-factors and recent household diarrhea are presented in Table 1 and findings from the logistic regression are summarized in Table 3. Results suggest that women with children had over four times the odds of reporting recent diarrhea in the family (OR $=4.3,95 \% \mathrm{CI}=1.42-12.75, p=.015)$ than women without children. Additionally, women in sanitation profile 2-those who rely on a toilet for defecation during the day, but utilize bags, buckets, or OD for urination during the day and for both urination and defecation at night-had over five times the odds of reporting at least one case of diarrhea in the family in the previous 2 weeks than women in other sanitation profiles $(\mathrm{OR}=5.2,95 \%$ $\mathrm{CI}=2.21-12.21, p=0.002$ ).

Women who relied on water from taps inside their homes had higher odds of reporting at least one case of recent diarrhea in the family compared to women who used public taps or wells $(\mathrm{OR}=3.8,95 \% \mathrm{CI}=1.33-10.82, p=$ 0.018). Women who reported that their toilets were clean had $62 \%$ lower odds of reporting a recent case of diarrhea in the family ( $95 \% \mathrm{CI}=0.20-0.72, p=.007)$ compared to women who reported their toilets were dirty/neither clean nor dirty. Women who had to go outside their homes to access a place to urinate/defecate, but walked $2 \mathrm{~min}$ or less had double the odds of reporting a case of recent diarrhea among members of the household compared to women who did not go outside their house to access a toilet/site for urination/defecation $(\mathrm{OR}=2.0,95 \% \mathrm{CI}=1.25-3.34$, $p=0.009$ ).

\section{Discussion}

The purpose of this study was to examine associations between characteristics of women's sanitation and 
hygiene knowledge, behaviors and environments and recent cases of diarrhea in the Mathare Valley informal settlement in Nairobi, Kenya. Diarrhea is one of the leading causes of death among children under 5 years and a serious contributor to the global burden of disease for people of all ages, especially in informal settlements in sub-Saharan Africa. Results of this study provide important information for developing better and more targeted intervention and policy strategies to prevent diarrhea in these rapidly expanding settlement environments.

Several findings from this study are consistent with evidence from other studies exploring factors associated with recent diarrheal infections in urban and peri-urban informal settlements. For example, women who reported that their toilets were clean in this study had lower odds of reporting recent diarrhea in the household. This is consistent with findings from other studies [11, 12] suggesting that the cleanliness of toilets is a key factor associated with diarrhea. Studies suggest this is particularly true in informal settlements where toilets are often shared between many families and the locus of responsibility for cleaning these toilets is not often clearly defined [35].

Primary water source-another common factor associated with diarrheal disease-was also associated with recent household diarrhea in this study. Women who reported using taps inside their buildings, plots, or houses had higher odds of recent household diarrhea than women who rely primarily on public wells or taps. Recent literature suggests that while public water kiosks and taps are usually operated by formally licensed providers in informal settlements in Nairobi and, consequently, are regulated, private vendors, e.g. households and/or landlords who supply water to their tenants in plots or buildings, are usually unregulated [36]. In light of literature focused on water providers in informal settlements in Kenya, the findings from this study may suggest that private water sources, e.g. those within households, plots, or buildings, may not be regulated and, consequently, unsafe for drinking.

Several previous studies have also found that the number of children in a household increases the risk of recent diarrhea $[5,10,37,38]$. Findings from this study suggest that women with children had higher odds of reporting at least one case of diarrhea in the household in the preceding 2 weeks, but, when controlling for other factors, the number of children did not have a significant association (results not shown).

Women in sanitation profile 2-those who rely primarily on toilets for defecation during the day, but use bags, buckets, and OD for urination during the day and for urination and defecation at night-had significantly higher odds of reporting acute diarrhea by at least one member of their household in the preceding 2 weeks. While it is difficult to determine precisely why women in this sanitation profile had higher odds of recent diarrhea among members of their household, it could be related to the type of facility these women use. All but one of the women in this profile, for example, rely on public toilets for defecation during the day (99.2\%). In order to test this hypothesis, we ran a separate logistic regression model (results presented in Appendix) to examine the relationship between women who relied on public toilets at least once in a 24 -h period and recent diarrhea in the household. Findings from this analysis suggest that women who use public toilets have higher odds of reporting recent diarrhea in the household compared to women who do not use public facilities $(\mathrm{OR}=2.3,95 \% \mathrm{CI}=1.54-3.3, p=0.001)$. The magnitude and significance of the other covariates and WASH-related factors in the model were similar to those in the primary logistic regression (See Appendix).

Interestingly, the number of people sharing women's toilets/sites for urination/defecation was not significantly associated with recent diarrhea in the family in the regression analysis, which is inconsistent with evidence from previous studies $[11,38]$. The association between use of public toilets, the majority of which are used by more than 100 people in Mathare (77\%), and recent household diarrhea may indicate that the type and management of a toilet and the relationship between the people using it may be of more importance than just the number of people sharing it. Finally, results from this study also suggested that distance (walk time) to reach a toilet was associated with higher odds of recent diarrhea-a finding that is consistent with other studies [11]. Walk time or distance to a toilet may also be an indication of the type of toilet facility on which women are relying. For example, mid-range walk times likely indicate the use of plot/building toilets or nearby public toilets while longer walk times likely indicate use of further public toilets or OD.

Interestingly, women in this study who relied exclusively on OD and/or bags or buckets in their homes and disposing of feces in open drainages outside their homes, i.e. those in sanitation profile 5 , did not have higher odds of reporting recent diarrhea compared to women using toilets as all times (sanitation profile 1) as has been found in previous studies [12]. This finding, however, may point to an important disconnect between individual- and public-health when it comes to sanitation. According to McGranahan [39] an individual's sanitation strategies can, in principal, be more clean, hygienic, safe, and private than other 
Table 2 Women's Water, Sanitation, and Hygiene (WASH) Knowledge $(n=550)$

\begin{tabular}{|c|c|c|c|c|c|c|}
\hline \multirow[t]{2}{*}{ Question } & \multirow[t]{2}{*}{ Summary of Responses } & \multicolumn{2}{|c|}{$\begin{array}{l}\text { Total } \\
\text { Population }\end{array}$} & \multicolumn{3}{|c|}{ Proportion with Recent Diarrhea } \\
\hline & & $\overline{\text { Count }}$ & $\%$ & Count & $\%$ of total sample & $\begin{array}{l}\text { \% for each } \\
\text { category }\end{array}$ \\
\hline \multirow{7}{*}{$\begin{array}{l}\text { What are the most common effects of } \\
\text { drinking unsafe water (more than one } \\
\text { answer is acceptable)? }\end{array}$} & Vomiting & 39 & 7.1 & 1 & 0.2 & 2.6 \\
\hline & Stomach ache & 42 & 7.6 & 6 & 1.1 & 14.3 \\
\hline & Amoeba & 64 & 11.6 & 13 & 2.4 & 20.3 \\
\hline & Infection & 10 & 1.8 & 1 & 0.2 & 10.0 \\
\hline & Typhoid & 168 & 30.5 & 36 & 6.5 & 21.4 \\
\hline & Cholera & 185 & 33.6 & 42 & 7.6 & 22.7 \\
\hline & Diarrhea & 271 & 49.3 & 31 & 5.6 & 11.4 \\
\hline \multirow{8}{*}{$\begin{array}{l}\text { Who do you think is most affected by } \\
\text { diarrhea (more than one answer is } \\
\text { acceptable)? }\end{array}$} & Adults & 1 & 0.2 & 0 & 0.0 & 0.0 \\
\hline & Children (under 5) & 263 & 47.8 & 38 & 6.9 & 14.4 \\
\hline & Elderly people & 25 & 4.5 & 6 & 1.1 & 24.0 \\
\hline & Pregnant women & 1 & 0.2 & 0 & 0.0 & 0.0 \\
\hline & Adult men & 0 & 0.0 & 0 & 0.0 & 0.0 \\
\hline & Adult women & 2 & 0.4 & 0 & 0.0 & 0.0 \\
\hline & Everyone & 309 & 56.2 & 55 & 10.0 & 17.8 \\
\hline & Other (specify) & 1 & 0.2 & 1 & 0.2 & 100.0 \\
\hline \multirow{10}{*}{$\begin{array}{l}\text { How does a person get diarrhea (more } \\
\text { than one answer is acceptable)? }\end{array}$} & Dirty hands & 450 & 81.8 & 80 & 14.5 & 17.8 \\
\hline & It's part of a child's growth & 60 & 10.9 & 8 & 1.5 & 13.3 \\
\hline & Black magic/witchcraft & 32 & 5.8 & 5 & 0.9 & 15.6 \\
\hline & Germs & 467 & 84.9 & 81 & 14.7 & 17.3 \\
\hline & Dirty food & 473 & 86.0 & 81 & 14.7 & 17.1 \\
\hline & Poor hygiene & 454 & 82.5 & 79 & 14.4 & 17.4 \\
\hline & Flies & 379 & 68.9 & 64 & 11.6 & 16.9 \\
\hline & Dirty water & 449 & 81.6 & 80 & 14.5 & 17.8 \\
\hline & $\begin{array}{l}\text { Open defecation/bags/ } \\
\text { buckets }\end{array}$ & 347 & 63.1 & 64 & 11.6 & 18.4 \\
\hline & Other (specify) & 11 & 2.0 & 0 & 0.0 & 0.0 \\
\hline \multirow{13}{*}{$\begin{array}{l}\text { How can you prevent yourself and your } \\
\text { family members from getting diarrhea } \\
\text { (more than one answer is acceptable)? }\end{array}$} & Do not know & 6 & 1.1 & 2 & 0.4 & 33.3 \\
\hline & Drink clean water & 492 & 89.5 & 83 & 15.1 & 16.9 \\
\hline & $\begin{array}{l}\text { Wash your food before } \\
\text { eating }\end{array}$ & 476 & 86.5 & 85 & 15.5 & 17.9 \\
\hline & Cook foods & 344 & 62.5 & 46 & 8.4 & 13.4 \\
\hline & Toilet use & 450 & 81.8 & 82 & 14.9 & 18.2 \\
\hline & Treating water & 434 & 78.9 & 78 & 14.2 & 18.0 \\
\hline & $\begin{array}{l}\text { Washing hands with } \\
\text { water and soap/ash }\end{array}$ & 428 & 77.8 & 77 & 14.0 & 18.0 \\
\hline & Covering food & 428 & 77.8 & 71 & 12.9 & 16.6 \\
\hline & $\begin{array}{l}\text { Avoiding open defecation/ } \\
\text { bags/buckets }\end{array}$ & 386 & 70.2 & 68 & 12.4 & 17.6 \\
\hline & $\begin{array}{l}\text { Going to a traditional } \\
\text { healer }\end{array}$ & 18 & 3.3 & 3 & 0.5 & 16.7 \\
\hline & Prayer & 71 & 12.9 & 9 & 1.6 & 12.7 \\
\hline & Storing water safely & 252 & 45.8 & 54 & 9.8 & 21.4 \\
\hline & Other (specify) & 5 & 0.9 & 0 & 0.0 & 0.0 \\
\hline Kindly give me the key times you usually & Never & 0 & 0.0 & 0 & 0.0 & 0.0 \\
\hline
\end{tabular}


Table 2 Women's Water, Sanitation, and Hygiene (WASH) Knowledge $(n=550)$ (Continued)

\begin{tabular}{|c|c|c|c|c|c|c|}
\hline \multirow[t]{2}{*}{ Question } & \multirow[t]{2}{*}{ Summary of Responses } & \multicolumn{2}{|c|}{$\begin{array}{l}\text { Total } \\
\text { Population }\end{array}$} & \multicolumn{3}{|c|}{ Proportion with Recent Diarrhea } \\
\hline & & Count & $\%$ & Count & $\%$ of total sample & $\begin{array}{l}\% \text { for each } \\
\text { category }\end{array}$ \\
\hline \multirow{11}{*}{$\begin{array}{l}\text { wash your hands (more than one answer } \\
\text { is acceptable)? }\end{array}$} & Before eating & 543 & 98.7 & 89 & 16.2 & 16.4 \\
\hline & After eating & 503 & 91.5 & 85 & 15.5 & 16.9 \\
\hline & After defecation & 417 & 75.8 & 76 & 13.8 & 18.2 \\
\hline & After urination & 300 & 54.5 & 59 & 10.7 & 19.7 \\
\hline & After toilet use & 485 & 88.2 & 81 & 14.7 & 16.7 \\
\hline & After handling animals & 148 & 26.9 & 12 & 2.2 & 8.1 \\
\hline & $\begin{array}{l}\text { After handling babies' } \\
\text { feces/diaper }\end{array}$ & 402 & 73.1 & 80 & 14.5 & 19.9 \\
\hline & After handling rubbish & 334 & 60.7 & 66 & 12.0 & 19.8 \\
\hline & When they are visibly dirty & 323 & 58.7 & 53 & 9.6 & 16.4 \\
\hline & After handling manure & 126 & 22.9 & 11 & 2.0 & 8.7 \\
\hline & Other (specify) & 5 & 0.9 & 1 & 0.2 & 20.0 \\
\hline
\end{tabular}

alternatives from the user's perspective, but still impose a heavy health burden onto others and the community as a whole. For example, women in Mathare may feel that OD and/or use of bags/buckets is a safer, more manageable, cleaner, or even hygienic option than a public or shared toilet; however, as soon as the raw sewage is left in the open or emptied into open drainages, everyone in the community is likely to be at greater risk. While exclusive use of OD or bags/buckets in the home may not increase the odds of individuals in that household getting diarrhea because, for example, women may work hard to ensure that the process is as hygienic as possible, women who rely exclusively on these strategies also do not show significantly lower odds of household diarrhea compared to women who utilize toilets at all times. This could be because the health burden of disposing of raw sewage in the environment is shared, more or less equally, by all in the local community.

According to literature, caregiver knowledge related to WASH and health can be an important protective factor to prevent diarrhea [7, 9]; yet, evidence of the association between WASH and health knowledge and diarrhea are sometimes mixed [40, 41]. Some studies suggest, for example, that high levels of overall WASH and health knowledge do not always lead to better diarrheal prevention behaviors [40, 41]-findings which are consistent with findings in this study. For example, over two-thirds of the women in this study identified OD and/or use of bags and buckets (emptied into open drainages) as a primary cause of diarrhea and $70 \%$ said avoiding OD and/or use of bags and buckets was a key diarrhea prevention strategy; yet, close to $69 \%$ of the women reported that they rely on bags or buckets for urination/defecation at night and an additional 6\% reported defecating in the open at night. One explanation for this findings might be, as evidence from other studies corroborates $[42,43]$, that there is a knowledge-behavior gap when it comes to issues of WASH. Women may know, for example, that use of OD and/or bags and buckets is linked to poor health outcomes, but abandoning these practices may be hindered by additional more-pressing factors that prevent women, and their children and family members, from accessing clean water, safe sanitation, and or products for safe hygiene [17, 44]. For example, several recent studies have provided evidence that women in sanitationpoor environments, e.g., informal settlements, often face a number of gender-specific barriers to access sanitation such as lack of privacy and dignity [18, 45, 46] and sexual violence and harassment associated with having to rely on community toilets or sites for $\mathrm{OD}$ at night or during menstruation [22, 45-48]. In this study, for example, $80 \%$ of women reported that it is not safe to go alone to a toilet at night-a barrier that may need to be addressed if women and, more than likely, their children are to consider abandoning the use of OD or bags and buckets, especially at night. An alternative explanation might be that women's WASH and health knowledge influences their decisions to use methods in their homes because they perceive them to be more hygienic than the alternatives. Literature suggests that shared sanitation in informal settlements may be associated with poor 
Table 3 Factors associated with reports of diarrhea in the household in the last 2 weeks $(n=550)$

\begin{tabular}{|c|c|c|c|}
\hline & Odds Ratio & $p$-value & $\mathrm{Cl} 95 \%$ \\
\hline \multicolumn{4}{|l|}{ Socio-Economic Factors } \\
\hline Age (continuous) & 1.03 & 0.167 & $0.985-1.077$ \\
\hline \multicolumn{4}{|l|}{ Education (less than complete primary) } \\
\hline Completed primary & 0.86 & 0.771 & $0.274-2.691$ \\
\hline Some secondary & 1.18 & 0.737 & $0.402-3.478$ \\
\hline Completed secondary & 1.11 & 0.786 & $0.475-2.603$ \\
\hline Employed & 2.12 & 0.069 & $0.931-4.809$ \\
\hline Married & 0.82 & 0.469 & $0.447-1.489$ \\
\hline Has children & 4.26 & 0.015 & $1.424-12.753$ \\
\hline \multicolumn{4}{|l|}{ Household income (ref: less than 5000/month) } \\
\hline Between Ksh 5000-10,000/month (US\$50-\$100) & 1.96 & 0.156 & $0.739-5.184$ \\
\hline More than Ksh 10,000/month (>US\$100) & 0.80 & 0.714 & $0.207-3.06$ \\
\hline \multicolumn{4}{|l|}{$\begin{array}{l}\text { Toilet descriptors } \\
\text { (ref: Profile 1: Day - toilet for urine/feces; nights - } \\
\text { toilet for urine/feces) }\end{array}$} \\
\hline $\begin{array}{l}\text { Profile 2: Day - toilet for urine/feces; night - } \\
\text { bags/buckets/OD for urine/feces }\end{array}$ & 1.57 & 0.212 & $0.737-3.354$ \\
\hline $\begin{array}{l}\text { Profile 3: Day - toilet for feces, bags/buckets/OD } \\
\text { for urine; night - bags/buckets/OD for urine/feces }\end{array}$ & 5.20 & 0.002 & $2.212-12.211$ \\
\hline $\begin{array}{l}\text { Profile 4: Day - toilet for urine/feces; night - toilet } \\
\text { for feces, bags/buckets/OD for urine }\end{array}$ & 0.74 & 0.322 & $0.395-1.4$ \\
\hline $\begin{array}{l}\text { Profile 5: Day - bags/buckets/OD for urine/feces; } \\
\text { night: bags/buckets/OD for urine/feces }\end{array}$ & 0.23 & 0.128 & $0.032-1.657$ \\
\hline \multicolumn{4}{|l|}{ Water source } \\
\hline \multicolumn{4}{|l|}{ Primary water source (ref: public tap/well) } \\
\hline Tap inside home/building & 3.79 & 0.018 & $1.329-10.818$ \\
\hline Tap outside home/building & 3.02 & 0.057 & $0.959-9.48$ \\
\hline Tanker/vendor & 1.72 & 0.295 & $0.578-5.095$ \\
\hline \multicolumn{4}{|l|}{ Toilet hygiene and accessibility } \\
\hline Toilets are clean & 0.38 & 0.007 & $0.198-0.723$ \\
\hline Toilets have running water/water for hygiene & 0.48 & 0.116 & $0.187-1.24$ \\
\hline $\begin{array}{l}\text { Maximum number of people sharing toilet(s) } \\
\text { (continuous) }\end{array}$ & 1.00 & 0.147 & $0.998-1$ \\
\hline \multicolumn{4}{|l|}{$\begin{array}{l}\text { Maximum walk time to toilet(s) (ref: does } \\
\text { not go out) }\end{array}$} \\
\hline 2 min or less & 2.04 & 0.009 & $1.249-3.336$ \\
\hline Between 3 and 4 min & 1.41 & 0.533 & $0.427-4.68$ \\
\hline At least 5 min & 0.58 & 0.246 & $0.218-1.55$ \\
\hline \multicolumn{4}{|l|}{ WASH knowledge and practices } \\
\hline Uses disinfectant (e.g. soap) to wash hands & 0.54 & 0.235 & $0.179-1.609$ \\
\hline Treats drinking water & 0.56 & 0.064 & $0.306-1.042$ \\
\hline Uses something other than tissue for anal cleansing & 1.15 & 0.682 & $0.54-2.472$ \\
\hline WASH knowledge score (continuous) & 1.08 & 0.130 & $0.972-1.21$ \\
\hline
\end{tabular}


health outcomes, e.g. diarrhea [31, 35, 49-51]; women may be using bags, buckets, or OD in or near the home not out of ignorance of the health risks, but rather because they perceive such practices to be healthier options than using shared sanitation facilities regardless of any greater environmental or public health implications.

Overall, findings from this study suggest that a number of characteristics of women's sanitation and hygiene knowledge, behaviors and environments are associated with recent cases of household diarrhea in Mathare. Findings suggest that women in this settlement are knowledgeable about WASH and health and adopt reasonable sanitation-management strategies in light of the numerous challenges they face in these settlements. Some of their sanitation-management strategies, e.g. relying on $\mathrm{OD}$ or using bags and buckets that are subsequently emptied into open drainages, may have serious public and environmental health implications; thus, it is critical to consider reasonable solutions to help women have more and better options for sanitation management. Given that findings from the research suggest women in Mathare are knowledgeable about WASH and health, solutions to sanitation issues in this settlement should focus on addressing other external factors that continue to limit women's ability to access sanitation, e.g. safety and privacy. A growing number of sanitation interventions have been implemented in Mathare in recent years, such as Sanergy's Fresh Life toilets, Grand Challenge Canada's funded Banza toilets, and/or National Youth Service's (NYS) slum improvement project toilets, to name a few, but little is known about the effect of these interventions on women's ability to consistently access sanitation throughout a 24-h period, changes in women's sanitation management strategies or on sanitation-related health outcomes like diarrhea. Findings from a recent article focused on women's solutions to sanitation challenges in Mathare, suggest that strategies aimed at supporting women's efforts for collective action around issues of sanitation and co-production efforts between landlords and governments may help women have more and better options to manage household sanitation more safely and, consequently, to reduce household diarrhea [23]. These collective action and co-production strategies are also in-line with the WHO's recent Guidelines on Sanitation and Health, which encourage sanitation strategies and interventions that combine government leadership, oversight, monitoring, and potential funding with locally delivered services [52].

There were several limitations to this study. For example, we relied on a self-reported measure of diarrhea provided by only one female resident of each household. While self-reported measures of two-week diarrhea provided by the primary caregiver (usually the mother) are common in studies assessing the prevalence of diarrhea among children under the age of 5 years, this study neither focused exclusively on under-5 children nor did it require that the female study participant be the primary caregiver in the household. Thus, the women in this study may not have been able to provide an accurate account of diarrhea for all members of the household, nor are their reported sanitation practices necessarily the same as those of other members of the household. Second, while this study included many of the common socio-economic, environmental, and WASH factors assessed in similar diarrhea prevalence studies, the list is not comprehensive. We did not, for example, include factors such as water quality measures, observed hygiene measures (e.g., presence of flies in house/on food/in toilets, observed feces in toilet facilities or in open drainages, sewage conditions, or garbage disposal methods), or medical factors (e.g., fever, stunting, and dehydration) - variables that have shown to be important risk or protective factors in other studies [10-12].

\section{Conclusion}

This study explored socio-economic, environmental, and WASH-related factors associated with recent diarrheal diseases in informal settlements in Nairobi, Kenya. While many of the findings are consistent with previous literature that emphasizes the importance of access to clean/safe sources of drinking water and nearby sanitary toilet facilities as protective factors for diarrhea, this study also suggests that there exists an important gap between WASH knowledge and behavior in this setting. Even though the majority of women in this study were able to correctly identify key times to wash their hands, common causes of diarrhea, and strategies to prevent diarrhea, they still engaged in behaviors that are associated with poor individual and/or public health outcomes. Findings from this study suggest that global health targets to reduce the prevalence of diarrheal diseases will not be met unless particular attention is paid to the needs of women living in informal settlements. For example, this study provides an evidence base for the profound role that women's sense of safety, fear of violence, and concern over the cleanliness of facilities play in their sanitation behaviors. Such externally driven factors will not be addressed solely through WASH and health education programs aimed at individuals. Interventions must also address the underlying, external factors that drive the gap between knowledge and behavior in these communities. 


\section{Appendix}

Table 4 Public toilet associated with reports of diarrhea in the household in the last 2 weeks $(n=550)$

\begin{tabular}{|c|c|c|c|}
\hline & Odds Ratio & $p$-value & $\mathrm{Cl} 95 \%$ \\
\hline \multicolumn{4}{|l|}{ Socio-Economic Factors } \\
\hline Age (continuous) & 1.03 & 0.219 & $0.981-1.076$ \\
\hline \multicolumn{4}{|l|}{ Education (less than complete primary) } \\
\hline Completed primary & 0.88 & 0.808 & $0.279-2.771$ \\
\hline Some secondary & 1.22 & 0.682 & $0.424-3.521$ \\
\hline Completed secondary & 1.01 & 0.989 & $0.4-2.526$ \\
\hline Employed & 2.17 & 0.046 & $1.016-4.613$ \\
\hline Married & 0.85 & 0.520 & $0.485-1.477$ \\
\hline Has children & 3.93 & 0.024 & $1.243-12.455$ \\
\hline \multicolumn{4}{|l|}{ Household income (ref: less than 5000/month) } \\
\hline Between Ksh 5000-10,000/month (US\$50-\$100) & 2.15 & 0.052 & $0.993-4.636$ \\
\hline More than Ksh 10,000/month (>US\$100) & 0.77 & 0.668 & $0.207-2.866$ \\
\hline \multicolumn{4}{|l|}{ Toilet descriptors } \\
\hline Public toilet & 2.25 & 0.001 & $1.542-3.284$ \\
\hline \multicolumn{4}{|l|}{ Water source } \\
\hline \multicolumn{4}{|l|}{ Primary water source (ref: public tap/well) } \\
\hline Tap inside home/building & 3.78 & 0.023 & $1.254-11.384$ \\
\hline Tap outside home/building & 2.83 & 0.054 & $0.977-8.173$ \\
\hline Tanker/vendor & 1.67 & 0.315 & $0.566-4.958$ \\
\hline \multicolumn{4}{|l|}{ Toilet hygiene and accessibility } \\
\hline Toilet(s) are clean & 0.44 & 0.014 & $0.241-0.814$ \\
\hline Toilet(s) have running water/water for hygiene & 0.53 & 0.209 & $0.186-1.517$ \\
\hline Maximum number of people sharing toilet(s) (continuous) & 1.00 & 0.353 & $0.999-1.002$ \\
\hline \multicolumn{4}{|l|}{ Maximum walk time to toilet(s) (ref: does not go out) } \\
\hline 2 min or less & 3.28 & 0.001 & $1.927-5.59$ \\
\hline Between 3 and 4 min & 2.15 & 0.157 & $0.705-6.586$ \\
\hline At least 5 min & 0.95 & 0.853 & $0.549-1.657$ \\
\hline \multicolumn{4}{|l|}{ WASH knowledge and practices } \\
\hline Uses disinfectant (e.g. soap) to wash hands & 0.69 & 0.413 & $0.262-1.815$ \\
\hline Treats drinking water & 0.55 & 0.068 & $0.285-1.056$ \\
\hline Uses tissue for anal cleansing & 1.22 & 0.551 & $0.594-2.513$ \\
\hline WASH knowledge score (continuous) & 1.10 & 0.059 & $0.996-1.216$ \\
\hline
\end{tabular}

\section{Abbreviations}

Cl: Confidence interval; DALYs: Disability-adjusted life years; KES: Kenya shilling; NACOSTI: National Commission for Science, Technology and Innovation; NYS: National Youth Service; OD: Open defecation; OR: Odds ratio; UNDESA: United Nations Department of Economic and Social Affairs; USD: United States dollar; VIF: Variance inflation factor; WASH: Water, sanitation, and hygiene; WASH-KAP: Water, sanitation, and hygiene knowledge, attitudes, and practices; WHO: World Health Organization

\section{Acknowledgements}

Not applicable.

\section{Funding}

The principal researcher on this project received two doctoral fellowships that allowed for the collection of this data: the National Security Education Program's David L. Boren Fellowship and PEO International's Scholar Award. The Boren fellowship mainly provided funding for the principal investigator to carry out the research. The PEO scholar award was used primarily to finance data collection, including field and equipment costs, participant fees, and research extender compensation, as well as some assistance for analysis, e.g., the purchase of statistical software.

\section{Availability of data and materials}

The dataset used and analyzed during the current study is available from the corresponding author on reasonable request. 


\section{Authors' contributions}

SW managed the data collection and analyzed the data. She was a major contributor in writing the manuscript. MD assisted in the collection of data. She was a major contributor in writing the manuscript. FB was a major contributor in writing the manuscript. All authors read and approved the final manuscript.

\section{Ethics approval and consent to participate}

This study protocol underwent ethics review by Kenya's National Commission for Science, Technology, and Innovation (references number: NACOST//P/15/ 7495/7482) and the Institutional Review Board at Rutgers University (reference number: 15-772 M). A waiver of documentation of consent was provided for this study under the US Code of Federal Regulations $45 \$ 46.117$ because surveys were anonymous; thus, written documentation of consent would have been the only record linking the subject and the research. All participants did, however, provide oral consent.

\section{Consent for publication}

Not applicable.

\section{Competing interests}

The authors declare that they have no competing interests.

\section{Publisher's Note}

Springer Nature remains neutral with regard to jurisdictional claims in published maps and institutional affiliations.

\section{Author details}

${ }^{1}$ Edward J. Bloustein School of Planning \& Public Policy Rutgers, The State University of New Jersey, 33 Livingston Avenue, New Brunswick, NJ 08901, USA. ${ }^{2}$ Department of Sociology and Social Work, University of Nairobi, Nairobi, Kenya.

Received: 31 August 2018 Accepted: 4 March 2019

\section{Published online: 11 March 2019}

\section{References}

1. Troeger C, Forouzanfar M, Rao PC, Khalil I, Brown A, Reiner RC Jr, Fullman N, Thompson RL, Abajobir A, Ahmed M. Estimates of global, regional, and national morbidity, mortality, and aetiologies of diarrhoeal diseases: a systematic analysis for the global burden of disease study 2015. Lancet Infect Dis. 2017;17(9):909-48.

2. World Health Organization. Preventing diarrhoea through better water, sanitation and hygiene: Exposures and impacts in low- and middle-income countries. Geneva: World Health Organization; 2014.

3. Clasen T, Pruss-Ustun A, Mathers CD, Cumming O, Cairncross S, Colford JM. Estimating the impact of unsafe water, sanitation and hygiene on the global burden of disease: evolving and alternative methods. Tropical Med Int Health. 2014;19(8):884-93.

4. Berendes DM, Kirby AE, Clennon JA, Agbemabiese C, Ampofo JA, Armah GE, Baker KK, Liu P, Reese HE, Robb KA, et al. Urban sanitation coverage and environmental fecal contamination: links between the household and public environments of Accra, Ghana. PLoS One. 2018;13(7):e0199304.

5. Kawakatsu Y, Tanaka J, Ogawa K, Ogendo K, Honda S. Community unit performance: factors associated with childhood diarrhea and appropriate treatment in Nyanza Province, Kenya. BMC Public Health. 2017;17(1):202.

6. African Population Health Research Center. Population and health dynamics in Nairobi's informal settlements: report of the Nairobi crosssectional slums survey (NCSS) 2000. Nairobi: African Population and Health Research Center; 2002.

7. Graf J, Meierhofer R, Wegelin M, Mosler H-J. Water disinfection and hygiene behaviour in an urban slum in Kenya: impact on childhood diarrhoea and influence of beliefs. Int J Environ Health Res. 2008;18(5):335-55.

8. African Population and Health Research Center (APHRC). Population and Health Dynamics in Nairobi's Informal Settlements: Report of the Nairobi Cross-sectional Slums Survey (NCSS) 2012. Nairobi: APHRC; 2014

9. George CM, Perin J, De Calani KJN, Norman WR, Perry H, Davis TP Jr, Lindquist ED. Risk factors for diarrhea in children under five years of age residing in peri-urban communities in Cochabamba, Bolivia. Am J Trop Med Hyg. 2014;91(6):1190-6.
10. Dos Santos S, de Charles Ouédraogo F, Soura AB. Water-related factors and childhood diarrhoea in African informal settlements. A cross-sectional study in Ouagadougou (Burkina Faso). J Water Health. 2015;13(2):562-74.

11. Adane M, Mengistie B, Kloos H, Medhin G, Mulat W. Sanitation facilities, hygienic conditions, and prevalence of acute diarrhea among under-five children in slums of Addis Ababa, Ethiopia: baseline survey of a longitudinal study. PLoS One. 2017;12(8):e0182783.

12. Ferdous F, Das SK, Ahmed S, Farzana FD, Malek MA, Das J, Latham JR, Faruque ASG, Chisti MJ. Diarrhoea in slum children: observation from a large diarrhoeal disease hospital in Dhaka, Bangladesh. Tropical Med Int Health. 2014;19(10):1170-6.

13. Ikua MD. Risk factors influencing diarrhoeal occurrence among children under five years old in informal urban settlements: A case study of Korogocho, in Nairobi County, Kenya. Nairobi: University of Nairobi; 2014.

14. Tornheim JA, Manya AS, Oyando N, Kabaka S, O'Reilly CE, Breiman RF, Feikin DR. The epidemiology of hospitalization with diarrhea in rural Kenya: the utility of existing health facility data in developing countries. Int J Infect Dis. 2010;14(6):e499-505.

15. Halvorson SJ. Women's management of the household health environment: responding to childhood diarrhea in the northern areas, Pakistan. Health Place. 2004;10(1):43-58.

16. Fisher J. Women in water supply, sanitation and hygiene programmes. In: Proceedings of The Institution of Civil Engineers - Municipal Engineer, vol. 161. Loughborough: ICE Publishing; 2008. p. 223-9. https://dspace.lboro.ac uk/dspace-jspui/bitstream/2134/9920/13/muen161-223.pdf.

17. Winter S, Dreibelbis R, Dzombo MN, Barchi F. A Mixed-Methods Study of Women's Sanitation Utilization in Informal Settlements in Kenya. PLOS One. In Press.

18. Corburn J, Hildebrand C. Slum sanitation and the social determinants of women's health in Nairobi, Kenya. J Environ Public Health. 2015;2015:1-6.

19. Winter S, Barchi F, Dzombo MN. Drivers of women's sanitation practices in informal settlements in sub-Saharan Africa: a qualitative study in Mathare Valley, Kenya. Int J Environ Health Res. 2018;28(6):609-25.

20. Mazeau AP. No toilet at home: Implementation, usage and acceptability of shared toilets in urban Ghana. Loughborough: Loughborough University; 2013.

21. Lagerkvist CJ, Kokko S, Karanja N. Health in perspective: framing motivational factors for personal sanitation in urban slums in Nairobi, Kenya, using anchored best-worst scaling. J Water Sanit Hyg Dev. 2014;4(1):108-19.

22. Khanna T, Das M. Why gender matters in the solution towards safe sanitation? Reflections from rural India. Glob Public Health. 2016;11(10):1185-201.

23. Winter S, Barchi F, Dzombo MN. Not just any toilet-women's solutions to sanitation in informal settlements in Nairobi. Dev Pract. 2019:29(1):15-25.

24. UNDESA. Internation decade for action 'Water for Life' 2005-2015: Gender and water Geneva: UNDESA: 2014.

25. Lundine J, Kovacic P, Poggiali L. Youth and digital mapping in urban informal settlements: lessons learned from participatory mapping processes in Mathare in Nairobi, Kenya. Child Youth Environ. 2012;22(2):214-33.

26. ESRI: ArcGIS Desktop. In., 10.3 edn. Redlands, CA: Environmental Systems Research Institute; 2015.

27. Kish L. Survey sampling. New York: Wiley and Sons, Inc; 1965.

28. Mattioli MC, Pickering AJ, Gilsdorf RJ, Davis J, Boehm AB. Hands and water as vectors of diarrheal pathogens in Bagamoyo, Tanzania. Environ Sci Technol. 2012;47(1):355-63.

29. Sibiya JE, Gumbo JR. Knowledge, attitude and practices (KAP) survey on water, sanitation and hygiene in selected schools in Vhembe district, Limpopo, South Africa. Int J Environ Res Public Health. 2013:10(6):2282-95.

30. Joshi A, Prasad S, Kasav JB, Segan M, Singh AK. Water and sanitation hygiene knowledge attitude practice in urban slum settings. Global J Health Sci. 2013;6(2):23

31. Fuller JA, Clasen T, Heijnen M, Eisenberg JN. Shared sanitation and the prevalence of diarrhea in young children: evidence from 51 countries, 2001-2011. Am J Trop Med Hyg. 2014;91(1):173-80.

32. Mbugua S, Musikoyo E, Ndungi F, Sang R, Kamau-Mbuthia E, Ngotho D. Determinants of diarrhea among young children under the age of five in Kenya, evidence from KDHS 2008-09. Afr Popul Stud. 2014:28(2):1046-56.

33. StataCorp: Statistical software. In., 14.0 edn. College Station, TX: StataCorp LP; 2015.

34. Schonlau M. Stata-ado package "hotdeckvar" for single hotdeck imputation; 2012

35. Tumwebaze IK, Niwagaba CB, Günther I, Mosler H-J. Determinants of households' cleaning intention for shared toilets: case of 50 slums in Kampala, Uganda. Habitat Int. 2014;41:108-13. 
36. United Nations Development Programme. Small-scale water providers in Kenya: Pioneers or predators? New york: United Nations Development Programme; 2011.

37. Mengistie B, Berhane $Y$, Worku A. Prevalence of diarrhea and associated risk factors among children under-five years of age in eastern Ethiopia: a crosssectional study. Open J Prev Med. 2013;3(07):446.

38. Thiam S, Diène AN, Fuhrimann S, Winkler MS, Sy I, Ndione JA, Schindler C, Vounatsou P, Utzinger J, Faye O. Prevalence of diarrhoea and risk factors among children under five years old in Mbour, Senegal: a cross-sectional study. Infect Dis Poverty. 2017;6(1):109.

39. McGranahan G. Realizing the right to sanitation in deprived urban communities: meeting the challenges of collective action, coproduction, affordability, and housing tenure. World Dev. 2015;68:242-53.

40. Merali HS, Morgan MS, Boonshuyar C. Diarrheal knowledge and preventative behaviors among the caregivers of children under 5 years of age on the Tonle Sap Lake, Cambodia. Res Rep Trop Med. 2018;9:35-24.

41. Greenland K, Chipungu J, Curtis V, Schmidt WP, Siwale Z, Mudenda M, Chilekwa J, Lewis JJ, Chilengi R. Multiple behaviour change intervention for diarrhoea control in Lusaka, Zambia: a cluster randomised trial. Lancet Glob Health. 2016:4(12):e966-77.

42. Schlegelmilch MP, Lakhani A, Saunders LD, Jhangri GS. Evaluation of water, sanitation and hygiene program outcomes shows knowledgebehavior gaps in Coast Province, Kenya. Pan Afr Med J. 2016;23(1):145.

43. Venkataramanan V, Crocker J, Karon A, Bartram J. Community-led total sanitation: a mixed-methods systematic review of evidence and its quality. Environ Health Perspect. 2018:26001:1.

44. Winter S, Dreibelbis R, Barchi F. Context matters: a multicountry analysis of individual and neighbourhood level factors associated with women's sanitation use in sub-Saharan Africa. Tropical Med Int Health. 2018;23(2): 173-92.

45. Sahoo KC, Hulland KR, Caruso BA, Swain R, Freeman MC, Panigrahi P, Dreibelbis R. Sanitation-related psychosocial stress: a grounded theory study of women across the life-course in Odisha, India. Soc Sci Med. 2015:139:80-9.

46. Sommer M, Ferron S, Cavill S, House S. Violence, gender and WASH: spurring action on a complex, under-documented and sensitive topic. Environ Urban. 2014;27(1):105-16.

47. Amnesty International. Insecurity and indignity: Women's experiences in the slums of Nairobi, Kenya. London: Amnesty International Publications; 2010.

48. Khosla R. Women and sanitation: urban reality experiences of government programmes, NGOs and CBOs. Social Change. 2000;30(1-2):192-207.

49. Simiyu S, Swilling $M$, Cairncross $S$. Decision-making on shared sanitation in the informal settlements of Kisumu, Kenya. Int J Environ Health Res. 2017; 27(5):377-93.

50. Kwiringira J, Atekyereza P, Niwagaba C, Günther I. Gender variations in access, choice to use and cleaning of shared latrines; experiences from Kampala slums, Uganda. BMC Public Health. 2014;14(1):1180.

51. Heijnen M, Cumming O, Peletz R, Chan GK-S, Brown J, Baker K, Clasen T. Shared sanitation versus individual household latrines: a systematic review of health outcomes. PLoS One. 2014;9(4):263-8.

52. World Health Organization. Guidelines on Sanitation and Health. Geneva: World Health Organization; 2018.

Ready to submit your research? Choose BMC and benefit from:

- fast, convenient online submission

- thorough peer review by experienced researchers in your field

- rapid publication on acceptance

- support for research data, including large and complex data types

- gold Open Access which fosters wider collaboration and increased citations

- maximum visibility for your research: over $100 \mathrm{M}$ website views per year

At $\mathrm{BMC}$, research is always in progress.

Learn more biomedcentral.com/submissions 